\title{
Joan W. ScoTT, La religion de la laïcité
}

Paris, Climats, 2018

\section{Philippe Ségur}

\section{OpenEdition}

\section{Journals}

Édition électronique

URL : http://journals.openedition.org/rdr/443

DOI : $10.4000 /$ rdr.443

ISSN : 2534-7462

\section{Éditeur}

Presses universitaires de Strasbourg

\section{Édition imprimée}

Date de publication : 14 novembre 2019

Pagination : 211-213

ISBN : 979-10-344-0054-6

ISSN : 2493-8637

\section{Référence électronique}

Philippe Ségur, « Joan W. scott, La religion de la laïcité », Revue du droit des religions [En ligne], 8 | 2019, mis en ligne le 25 novembre 2019, consulté le 19 novembre 2020. URL : http://

journals.openedition.org/rdr/443; DOI : https://doi.org/10.4000/rdr.443

Ce document a été généré automatiquement le 19 novembre 2020.

\section{(c) (1) (5)}

La revue du droit des religions est mise à disposition selon les termes de la Creative Commons Attribution - Pas d'Utilisation Commerciale 4.0 International - CC BY-NC 4.0. 


\section{Joan W. ScoTT, La religion de la laïcité}

Paris, Climats, 2018

Philippe Ségur

\section{RÉFÉRENCE}

Joan W. scotT, La religion de la laïcité, Paris, Climats, 2018, 318 p.

1 Prenant à rebours l'idée commune selon laquelle la laïcité protège les femmes contre l'oppression de l'islam et leur garantit l'égalité avec les hommes, l'auteur, professeure émérite à l'Université de Princeton, entend démontrer que l'inégalité de genre est au cœur de la séparation des Églises et de l'État qui fonde la modernité occidentale. Dès son propos introductif, elle avertit qu'elle va juxtaposer «des exemples de lieux d'histoires et de géographies diverses » en procédant «à gros traits» (p. 16-17). Sur ce point, le lecteur ne sera pas déçu. Si, en effet, le cas de la France est souvent sollicité, à de rares exceptions près les travaux des auteurs français contemporains, sociologues, historiens, juristes ou politologues, ne sont guère cités (on pensera, entre autres, à ceux de Jean Baubérot sur l'inexistence du modèle français de la laïcité, de Rita HermonBelot sur les sources révolutionnaires de l'idée laïque, de Sandrine Dauphin sur l'État et le droit des femmes ou de Réjane Sénac sur le genre et la parité). De même, on pourra regretter que l'analyse liminaire $\mathrm{du} \mathrm{xIX}^{\mathrm{e}}$ siècle français ne s'appuie que sur le Grand Robert de la langue française : cela conduit l'auteur à situer justement l'apparition du mot laïcité en 1871, mais en confondant la Commune de Paris avec une III République qui, dès cette époque, aurait combattu les partis monarchistes et l'Église (sic, p. 21).

Pouvait-on, du reste, parler de la laïcité comme d'un objet présumé identique en France, aux États-Unis et dans les autres États européens ? Il y a entre le mot français « laïcité » et l'anglais « secularism », mais aussi entre les termes français "laïcité » et «sécularisation », employés indifféremment dans ce texte, d'importantes nuances de sens qui auraient mérité un éclaircissement préalable. Il est certain que les précautions qu'impose leur usage dans des contextes culturels et juridiques différents auraient permis d'éviter quelques écueils et des schématisations hâtives. 
3 Sur le fond, Joan W. Scott s'attache à saisir la laïcité comme "catégorie discursive » pour montrer comment celle-ci sert de voile mystificateur à une discrimination persistante à l'égard des femmes tout en servant au maintien d'un discours culturaliste et racial hostile à l'islam. En effet, la laïcité servirait à définir l'identité de l'État-nation par exclusion de la différence raciale - où l'auteur mêle, au prix de quelques raccourcis, racisme idéologique, colonialisme et ethnocentrisme chrétien - et par inclusion de la différence de genres. Le discours sur la laïcité n'intégrerait le genre que racialisé en postulant une égalité des sexes en son sein et en dénonçant les discriminations à l'égard des femmes en dehors de lui, c'est-à-dire dans l'islam. La division libérale binaire du monde (public/privé, polis/marché, État/religion) aurait assigné les femmes à la sphère familiale et religieuse par effet d'un "sécularisme judéo-chrétien ", pour reprendre la formule d'Elizabeth Hurd (p. 49). Cette spécialisation des fonctions selon le sexe, attribuée d'abord à la biologie, s'inscrirait aussi dans une visée évolutionniste. Une différenciation sexuelle accrue, cantonnant les femmes dans des rôles sociaux secondaires, serait le résultat d'une idéologie techno-scientiste qui aurait vu dans la rationalité, biologiquement dévolue aux hommes, l'expression même du progrès humain (p. 96).

4 Joan W. Scott retrace les temps forts de cette évolution (police du mariage, promotion de la famille nucléaire, morale sexuelle, division du travail, exclusion du suffrage) qui, dans les discours et les actes, en Europe comme aux États-Unis, a développé, du $\mathrm{XVI}^{\mathrm{e}}$ siècle à la fin $\mathrm{du} \mathrm{xx}^{\mathrm{e}}$ siècle, une spécialisation sexuelle discriminatoire à l'égard des femmes. Cependant on peine souvent à établir le lien entre cette histoire du sexisme et la laïcité, faute d'une argumentation conceptuelle plus soutenue et en raison d'un crossover permanent entre diverses disciplines.

5 L'articulation entre sexisme et ethnocentrisme culturel souffre parfois des mêmes faiblesses. Il est difficile de situer sur le même plan - et dans le même développement la propagande durant la Guerre froide, la politique internationale des États-Unis après le 11 septembre 2001, des déclarations de Gorge W. Bush, de Nicolas Sarkozy et d'Angela Merkel et les travaux de Jürgen Habermas et de Benoît XVI sans courir le risque de perdre le lecteur ou de soutenir un propos superficiel et réducteur (p. 179-183). Malgré ces défauts, l'ouvrage s'achève sur une analyse critique intéressante de l'émancipation sexuelle. Au-delà des stéréotypes sur la libération de la femme occidentale et sur l'asservissement de la femme musulmane, Joan W. Scott note combien, dans la rhétorique laïque, la représentation de l'humain désormais a changé : «dans leurs usages dominants, les notions d'émancipation et d'égalité dissolvent toute distinction public/privé pour introduire de manière explicite une logique marchande dans le domaine politique » (p. 240). L'émancipation des femmes par la laïcité se révèle alors autant l'instrument d'un nouvel impérialisme culturel qu'un droit politique formel au sens où Marx l'entendait. 


\section{AUTEURS}

PHILIPPE SÉGUR

Professeur de droit public, Université de Perpignan Via Domitia, Centre du droit économique et du développement (CDED) 